\section{6 Whither British science?}

SIR-I wish to support what M.H. Dodson says on science teaching (Nature 333, 9; 1988) and to ask, now that the first examinations for the new General Certificate of Secondary Education (GCSE) have been held, whether people not teaching at this level are aware of what has been done in the name of improving British science education.

My personal commitment is to balanced science: all students should be exposed to the different disciplines of physics, chemistry and biology. Job advertisements for teachers show that the state schools have almost all adopted double award schemes, giving students two credits for 'science' rather than single credits for physics, chemistry or biology.

These double-award syllabuses have been supported by many distinguished bodies from the Royal Society down, so this is in no way surprising. Indeed, they are absolutely appropriate for most students and are a major advance for those who would previously have done little science after the age of 13 , possibly even none. Yet I do not believe that this is a sufficient diet for able students whom we hope to encourage to study sciences later, at school and university.

To allow all science to be taught within 20 per cent of curriculum time, to accommodate the assessed practical components and to make the syllabuses and examinations accessible to all students, content has been diluted so that required knowledge is superficial - even in single subject syllabuses. Biology has lost its bite and chemistry has become a trivial pursuit. Physics is no longer mathematical.

Double-award schemes simplify still further, especially when they encompass geology, meteorology and astronomy. Time allocations and common papers for all abilities discourage the pursuit of any topic in depth. It is not the absence of particular facts that worries me, but the lack of concepts that will capture the imagination of able pupils and allow them to see that science is an intellectual challenge worthy of further study.

Many of the questions set in this year's papers are an insult to students of ability and can serve only to lower the status of science in their eyes. We old hands will continue to try to develop our pupils' appreciation and understanding beyond syllabus demands but it will not be long before most science teaching is aimed only at the levels required by syllabus and examination - especially by subject specialists teaching their two non-specialist sciences. Pupils of ability will be able to gain greater intellectual satisfaction from arts subjects such as English, history and foreign languages. There are no double awards here and teachers can still select Macbeth as a set book rather than Adrian
Mole. So my fear is that although the new schemes may encourage some pupils to take up science who would not have done so before (and who will almost certainly drop out when they find the going is tougher at Advanced level) we will at the same time cause many able pupils to in the sixth form.

Finally, a reminder that what ultimately attracts able students to study a subject further is good teachers. The recent Smithers report on the shortage of physics ates teaching in any one of 28 randomly selected state schools for $11-16$ year-olds. Teaching science in these schools rather than three separate sciences may be a pragmatic solution to the present problem but can serve only as a disincentive to graduates of quality who might otherwise have thought of entering the profession. A sight of some of this year's papers should be sufficient to frighten away any who may still have been havering. One physics question gave a velocity time graph for a parachutist. It showed a decreasing accelto terminal velocity without the parachute. Another sharp discontinuity as the parachute opened was followed by constant retardation to the lower terminal velocity! Simplification is one thing but asking questions about data that are patently nonsense to many candidates is inexcusable.

So my plea to those schools still free to choose is to hold the line for their best students, to stick with separate subject sciences, to teach beyond these and to press for examinations in which able candidates do not have to sit the trivial papers designed for lower ability candidates.

ARTHUR J. KAHN

Manchester Grammar School,

Manchester M130XT, UK

\section{Polar observatories}

SIR-Dreadco's daring projects as described in your journal's weekly column Daedalus have stimulated our imagination. An endeavour that would be of the greatest importance for the astronomical community has occurred to us. In spite of Dreadco's reputation, we do not hesitate to mention it in this letter (with the request to forward it to their research department); the profits made if the idea were realized would still be justifiable in view of the benefits for mankind.

It turns out that there are several compelling reasons for considering Antarctic mountains as sites for new astronomical observatories. With every significant astronomical organizations in the world planning $8-\mathrm{m}$ class telescopes, the need for new high-quality and original choose arts subjects rather than sciences teachers found no trained physics gradueration followed by a sharp discontinuity sites will soon become acute. The Antarctic offers itself through the availability of high mountains. Conventional astronomy in the visible would benefit because a location near the geographic pole makes possible continuous observations for many days or even months (of exceptional value for measurements of stellar oscillations and variable regions). The very low moisture content of the Antarctic atmosphere, as well as the natural near-cryogenic environment, would be optimal for infrared observations. The most significant advantage, however, lies in the revolutionary possibilities for ultraviolet observations directly from the Earth's surface. The ozone hole currently developing in the Antarctic, tragic though its consequences may be elsewhere, would greatly reduce atmospheric absorption in the near-ultraviolet. Dreadco's scientists may easily convince themselves that a reduction of the ozone content to 10 per cent (which may be realistic in the near future) might allow astronomers to extend observations by as much as $30 \mathrm{~nm}$ or more into the ultraviolet. Searches for very distant quasars would benefit especially at they are most easily recognized by features in this wavelength region. An extension of the size of the known Universe by as much as 50 per cent certainly seems possible. Finally, sociologists may be interested in studying the interactions taking place in a group of respectable quasar specialists working together for the duration of an Antarctic winter.

H. C. Spruit

A. M. TitLe

R. C. Peterson

Max-Planck-Institut für Physik

and Astrophysik,

Institut für Astrophysik,

D-8046 Garching bei München, FRG

\section{Wrong number}

SIR-In the article "Scientists involved in Armenian environmental demonstrations" (Nature 332, 6; 1988), Vera Rich quotes Moscow radio world service's estimation of the ethnic composition of the Nagorno-Karabach region of the Soviet Union as 18 per cent Armenian. The truth is that radio reports announced 80 per cent Armenian, so the official commentators did not give "widely varying estimates".

The ethnic structure of the NagornoKarabach region, based on the most recent population census (1979) is: Azerbaijanis, 37,000 (22.8 per cent); Armenians, 123,000 (75.9 per cent); Russians, 1,300 (0.8 per cent); others, 700 ; making a total of 162,000 people.

WAGNER IOTOV Department of Genetics of RNA-Viruses, Institute of Viral Preparations, 109088 Moscow

USSR 